\title{
Application of flow cytometry for the identification of Staphylococcus epidermidis by peptide nucleic acid fluorescence in situ hybridization (PNA FISH) in blood samples
}

\author{
N. F. Azevedo $\cdot$ T. Jardim $\cdot$ C. Almeida $\cdot$ \\ L. Cerqueira $\cdot$ A. J. Almeida $\cdot$ F. Rodrigues $\cdot$ \\ C. W. Keevil • M. J. Vieira
}

Received: 13 April 2011/Accepted: 20 May 2011/Published online: 3 June 2011

(C) Springer Science+Business Media B.V. 2011

\begin{abstract}
Staphylococcus epidermidis is considered to be one of the most common causes of nosocomial bloodstream infections, particularly in immune-compromised individuals. Here, we report the development and application of a novel peptide nucleic acid probe for the specific detection of $S$. epidermidis by fluorescence in situ hybridization. The theoretical estimates of probe matching specificity and sensitivity were 89 and $87 \%$, respectively. More importantly, the probe was shown not to hybridize with closely
\end{abstract}

N. F. Azevedo ( $\square)$ · T. Jardim · C. Almeida .

L. Cerqueira · M. J. Vieira

IBB, Institute for Biotechnology and Bioengineering,

Centre of Biological Engineering, Universidade do

Minho, Campus de Gualtar, 4710-057 Braga, Portugal

e-mail: nazevedo@fe.up.pt

T. Jardim

e-mail: tatianajardim@gmail.com

C. Almeida

e-mail: carinaalmeida@deb.uminho.pt

L. Cerqueira

e-mail: lauracerqueira@deb.uminho.pt

M. J. Vieira

e-mail: mjv@deb.uminho.pt

N. F. Azevedo - C. Almeida · C. W. Keevil

Environmental Healthcare Unit, School of Biological

Sciences, University of Southampton, Highfield Campus,

Southampton SO17 1BJ, UK

e-mail: C.W.Keevil@soton.ac.uk related species such as Staphylococcus aureus. The method was subsequently successfully adapted for the detection of $S$. epidermidis in mixed-species blood cultures both by microscopy and flow cytometry.

Keywords Staphylococcus epidermidis . Bloodstream infection · Flow cytometry · FISH . Nanodiagnostics · Permeabilization
A. J. Almeida · F. Rodrigues
Life and Health Sciences Research Institute (ICVS),
School of Health Sciences, University of Minho, Braga,
Portugal
e-mail: agostinhoa@gmail.com
F. Rodrigues
e-mail: frodrigues@ecsaude.uminho.pt
N. F. Azevedo
LEPAE, Department of Chemical Engineering, Faculty of Engineering, University of Porto, Porto, Portugal 


\section{Introduction}

Staphylococcus epidermidis is a Gram-positive, coccoid bacterium that can be frequently isolated from the skin and mucous membranes of humans and animals. S. epidermidis is considered to be one of the most common causes for nosocomial bloodstream infections, particularly in immune-compromised individuals, hence labelling it as an opportunistic pathogen (Vuong and Otto 2002). Despite the recent appearance of molecular diagnostic methods, namely those based on real-time PCR and quantitative PCR (e.g. Jukes et al. 2010), the method of choice for the detection of $S$. epidermidis in clinical samples still relies on relatively slow cultivation techniques (Haimi-Cohen et al. 2002; Larsen et al. 2008). It is therefore of the utmost importance to develop novel methods, that are both rapid and robust, to assess the presence of this important pathogen.

Fluorescence in situ hybridization (FISH) is rapidly becoming one of the most established molecular biology techniques, and has now been widely applied to the detection of pathogens and associated antibiotic resistances in clinical samples for patient management (Barken et al. 2007; Trebesius et al. 2000). Nevertheless, problems associated with this method such as low affinity and specificity of the DNA probe for its target, inefficient probe diffusion through the cell membrane and degradation of the probe by endonucleases have hindered a more widespread application. In fact, the first DNA FISH probe targeting $S$. epidermidis can be traced back to the early 1990s (Zakrzewskaczerwinska et al. 1992), but has so far failed to have a commercial impact in clinical settings.

At approximately the same time, Nielsen et al. (1991) reported the development of a synthetic DNA analogue, named peptide nucleic acid (PNA). This molecule proved to be capable of forming PNA/DNA and PNA/RNA hybrids of complementary nucleic acid sequences, and its neutrally charged polyamide backbone made PNA FISH procedures easier and more efficient (Almeida et al. 2011; Cerqueira et al. 2008; Stender et al. 2002). Consequently, there have been several reports describing the development and application of novel PNA probes for the identification of several clinically relevant microorganisms, including S. aureus (Hartmann et al. 2005), Helicobacter pylori (Guimaraes et al. 2007), Cronobacter spp.
(Almeida et al. 2009) and Candida albicans (Oliveira et al. 2001). Some of these probes are already commercially available for clinical diagnosis.

In this work we report the development of a novel PNA probe for the specific detection of S. epidermidis by FISH in blood cultures. In addition, the suitability of microscopy and flow cytometry to obtain a successful diagnosis was assessed.

\section{Design, synthesis and solubilization of the PNA oligonucleotide probe}

As the original DNA probe for S. epidermidis dated back to 1992, and rRNA databases have greatly expanded since then, we decided to perform a reassessment of possible probes for PNA FISH. To identify other potentially useful oligonucleotides, the Primrose program was used coupled with the $16 \mathrm{~S}$ rRNA databases of the Ribosomal Database Project II (RDP II) version 9.55 (Ashelford et al. 2002; Cole et al. 2005). The selection of oligonucleotides was based on the 16S rRNA comparison of all S. epidermidis strains in the database. The main criterion for the selection of the PNA probe sequence was a balance between the detection of the highest number of S. epidermidis targets (sensitivity) together with the detection of the lowest number of non-target microorganisms (specificity). After possible probe sequences were selected, a BLAST and Probe Match search was performed to further confirm probe specificity (McGinnis and Madden 2004).

Probe Sep148 final sequence was 5'-AATATATTATCCGGT- $3^{\prime}$; the probe was named after the starting position of the complementary sequence on S. epidermidis ATCC 14990 16S rRNA (Accession number S000413964). The theoretical sensitivity and specificity of Sep148 and the earlier probe, calculated as described in Guimarães et al. (2007), are indicated in Table 1. Both parameters are higher for the new probe, which reflects the need to continuously reassess the sequences that are in use for targeting microorganisms, as nucleic acid sequences are added to the databases regularly. In any case, Sep148 still detected a small number of strains of S. lentus and S. simiae, together with one strain of Lysinibacillus sphaericus and of $S$. aureus. Apart from the latter, neither of these microorganisms is known to cause bloodstream infection in humans. As the probe only 
Table 1 Predicted specificity and sensitivity of existing probes for detection of S. epidermidis

\begin{tabular}{llll}
\hline Probe & Specificity (\%) & Sensitivity (\%) & Reference(s) \\
\hline Sep-1; pSe ${ }^{\mathrm{a}}$ & 83.9 & 80.4 & Krimmer et al. (1999), Zakrzewskaczerwinska et al. (1992) \\
Sep148 & 89.4 & 86.6 & This work \\
\hline
\end{tabular}

Last accession to the RDP-II database on the 27/12/2010

a Sequence of the probe pSe/Sep-1 is 5'-ACTCTATCTCTAGAGGGGTCAG-3'

detected one strain of $S$. aureus out of more than 100 existent in the database, it is reasonable to extrapolate that the actual specificity of the test in clinical settings will be even higher than the value obtained here.

Probe Sep148 was then synthesized (Panagene, Daejeon, South Korea) and the oligonucleotide $\mathrm{N}$ terminus attached to an Alexa fluor 488 dye via a double AEEA linker. The probe was then solubilised in $10 \%$ of acetonitrile and $1 \%$ of trifluoracetic acid to obtain a $100 \mu \mathrm{M}$ stock solution. The solubilization solution proved to be an essential step for this probe to work, as neither water nor dimethylformamide nor acetonitrile or trifluoroacetic acid individually seemed to be able to solubilise the probe in a satisfactory way. This might be attributed to a strong secondary structure of the probe, as predicted by the DINAMelt Server (http://www.bioinfo.rpi.edu) (Markham and Zuker 2005).

\section{Hybridization procedures on glass slides and in suspension}

The hybridization procedures were developed to detect $S$. epidermidis both on glass slides and in suspension. The bacterial species used to assess the specificity and sensitivity of the method are listed in Table 2. All bacterial species were maintained on Tryptic Soy Agar (TSA) (VWR, Portugal) at $37^{\circ} \mathrm{C}$ and streaked onto fresh plates every $24 \mathrm{~h}$. Before testing with PNA FISH, cells from 1 day old cultures were harvested from TSA plates, suspended in sterile water and homogenised by vortex for $1 \mathrm{~min}$.

For fixation on glass slides, smears of each species/strain tested were immersed in $4 \%(\mathrm{wt} / \mathrm{vol})$ paraformaldehyde followed by $50 \%$ ( $\mathrm{vol} / \mathrm{vol}$ ) ethanol for $10 \mathrm{~min}$ each and allowed to air dry. The smears were then covered with $20 \mu \mathrm{l}$ of the hybridization solution already described (Stender et al. 1999), together with $500 \mathrm{nM}$ of the Sep148 PNA probe. Samples were covered with coverslips, placed in moist chambers and incubated for $90 \mathrm{~min}$ at $50^{\circ} \mathrm{C}$. Subsequently, the coverslips were removed and the slides submerged in a prewarmed washing solution $\left(50^{\circ} \mathrm{C}\right)$ containing $5 \mathrm{mM}$ Tris Base, $15 \mathrm{mM} \mathrm{NaCl}$ and $1 \%$ ( $\mathrm{vol} / \mathrm{vol})$ Triton $\mathrm{X}(\mathrm{pH} \mathrm{10)}$. All these reagents except the PNA probe were acquired from Sigma. Washing was performed at $50^{\circ} \mathrm{C}$ for $30 \mathrm{~min}$ and the slides allowed to air dry. The smears were mounted with one drop of nonfluorescent immersion oil (Merck) and covered with coverslips. The slides were stored in the dark for a maximum of $24 \mathrm{~h}$ before microscopy.

The hybridization method in suspension was based on the procedure referred in Perry-O' Keefe et al. (2001) with slight modifications. In short, $1 \mathrm{ml}$ of cell suspension was pelleted by centrifugation at $10,000 \mathrm{rpm}$ for $5 \mathrm{~min}$, resuspended in $400 \mu \mathrm{l}$ of $4 \%$ (w/v) paraformaldehyde (Sigma) and fixed for $30 \mathrm{~min}$. The fixed cells were rinsed in autoclaved water, resuspended in $400 \mu \mathrm{l}$ of $50 \%$ ( $\mathrm{vol} / \mathrm{vol})$ ethanol and incubated, at least, for $30 \mathrm{~min}$ at $-20^{\circ} \mathrm{C}$. Subsequently, $100 \mu \mathrm{l}$ of the fixed cells aliquot was pelleted by centrifugation and rinsed with sterile water, resuspended in $100 \mu$ of hybridization solution with $500 \mathrm{nM}$ of PNA probe (as described above) and incubated at $50^{\circ} \mathrm{C}$ for $30 \mathrm{~min}$. After hybridization, cells were centrifuged at $10,000 \mathrm{rpm}$ for $5 \mathrm{~min}$, resuspended in $500 \mu \mathrm{l}$ of wash solution (as described above) and incubated at $50^{\circ} \mathrm{C}$ for $15 \mathrm{~min}$. This step was repeated one more time. The washed suspension was centrifuged and suspended in $500 \mu \mathrm{l}$ of sterile water. Finally, $20 \mu \mathrm{l}$ of the cell suspension were dispensed on a microscope slide or $200 \mu$ were filtered through a membrane (pore $0.2 \mu \mathrm{m}$, Cellulose Nitrate, Whatman) for microscopic observation. Alternatively, the suspension was used directly for flow cytometric analysis. Samples were stored in the dark for a maximum of $24 \mathrm{~h}$ before analysis. 
Table 2 Species of $S$. epidermidis and related species used in this study, together with the outcome of the PNA FISH method as assessed by microscopy and flow cytometry

\begin{tabular}{|c|c|c|}
\hline Organism & Mismatches & $\begin{array}{l}\text { PNA FISH } \\
\text { result }\end{array}$ \\
\hline $\begin{array}{l}\text { Staphylococcus epidermidis } \\
\text { ATCC } 35983\end{array}$ & 0 & + \\
\hline $\begin{array}{l}\text { Staphylococcus epidermidis } \\
\text { ATCC } 35894\end{array}$ & 0 & + \\
\hline $\begin{array}{l}\text { Staphylococcus epidermidis } \\
\text { ATCC } 1798 / 12228\end{array}$ & 0 & + \\
\hline $\begin{array}{l}\text { Staphylococcus epidermidis } \\
\text { ATCC } 14990\end{array}$ & 0 & + \\
\hline Staphylococcus epidermidis 75 & 0 & + \\
\hline Staphylococcus epidermidis 214 & 0 & + \\
\hline Staphylococcus epidermidis 816 & 0 & + \\
\hline Staphylococcus epidermidis 1457 & 0 & + \\
\hline Staphylococcus epidermidis 9142 & 0 & + \\
\hline $\begin{array}{l}\text { Staphylococcus epidermidis } \\
\text { 1457-M10 }\end{array}$ & 0 & + \\
\hline Staphylococcus epidermidis M10 & 0 & + \\
\hline Staphylococcus epidermidis LE7 & 0 & + \\
\hline $\begin{array}{l}\text { Staphylococcus aureus } \\
\text { ATCC } 13565\end{array}$ & $1 *$ & - \\
\hline $\begin{array}{l}\text { Staphylococcus aureus } \\
\text { ATCC } 12600\end{array}$ & 1 & - \\
\hline $\begin{array}{l}\text { Staphylococcus aureus } \\
\text { ATCC } 6538\end{array}$ & $1 *$ & - \\
\hline $\begin{array}{l}\text { Enterobacter aerogenes } \\
\text { ATCC } 13048\end{array}$ & $7 *$ & - \\
\hline $\begin{array}{l}\text { Enterobacter amnigenus } \\
\text { ATCC } 33072\end{array}$ & $7 *$ & - \\
\hline $\begin{array}{l}\text { Enterobacter sakazakii } \\
\text { ATCC } 29544\end{array}$ & 6 & - \\
\hline
\end{tabular}

- Number of expected mismatches based on the sequence of other strains

* Sequence not available (or short sequence that do not include the target region)

All experiments were repeated at least three times. For all of them, negative controls were performed simultaneously, where every step described in this section was also carried out, but where no probe was added during the hybridization step.

\section{Microscopic visualization and flow cytometry analyses}

Microscopic observation was performed using an Olympus BX51 epifluorescence microscope (OLYMPUS
Portugal SA, Porto, Portugal), equipped with one filter sensitive to the Alexa fluor 488 signalling molecule attached to the PNA probe (Excitation $470-490 \mathrm{~nm}$, Emission LP $516 \mathrm{~nm}$ ). Other filters present in the microscope, which were not capable of detecting the probe's fluorescent signal, were used to control for autofluorescence of the cells. Microscopy confirmed the high specificity and sensitivity predicted using in silico analysis, with all $S$. epidermidis strains hybridizing with the probe while closely related species failed to do so (Table 2 and Fig. 1a, b). To assess if $S$. epidermidis and $S$. aureus could be discriminated under the microscope, a suspension containing cells of both microorganisms in equal proportions was submitted to the hybridization process described above. In order to be able to observe non-hybridized cells under the microscope, the suspension was then counterstained with the non-specific dye 4'-6-diamidino-2phenylindole (DAPI, Sigma; $100 \mu \mathrm{g} / \mathrm{ml}$ ) as described in Almeida et al. (2011). Figure 1c discriminates two populations of cells in roughly the same proportion, which provides a strong indication that the signalto-noise ratio was adequate to discriminate both populations by microscopy.

In order to assess the suitability of this PNA FISH method to be detected by flow cytometric analysis, hybridized and non-hybridized cells were processed through an EPICS XL-MCL (Beckman-Coulter Corporation, Hialeah, Fl, USA) flow cytometer equipped with an argon-ion laser emitting a $488 \mathrm{~nm}$ beam at 15 $\mathrm{mW}$. A minimum of 30,000 cells per sample were acquired at low flow rate and an acquisition protocol was defined to measure forward scatter (FS LOG) and side scatter (SS LOG) on a four-decade logarithmic scale for initial scatter discrimination of general cell population and green fluorescence (FL1) on a logarithmic scale; this used the Multigraph software included in the system II acquisition software for the EPICS XL/XL-MCL version 1.0. Offline data were analyzed with the Windows Multiple Document Interface for Flow Cytometry 2.9 (WinMDI 2.9). This experiment was performed in triplicate for four different S. epidermidis strains (ATCC 35983, ATCC 35894, ATCC 1798/12228 and ATCC 14990) and also for one $S$. aureus type strain.

Flow cytometric analysis was also able to differentiate between $S$. epidermidis hybridized and nonhybridized cells independently of the tested strain (Fig. 2a, b). In fact, the observed increase in mean 


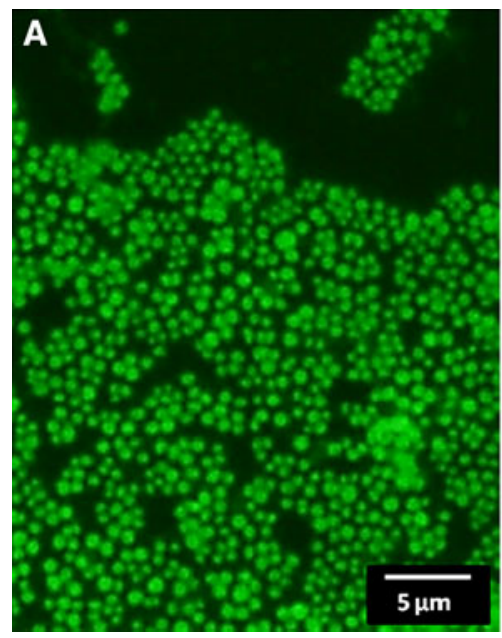

Fig. 1 Identification of $S$. epidermidis cells labeled with Sep148 by epifluorescence microscopy. a Observation of hybridized cells of S. epidermidis ATCC 12228. b Lack of hybridization signal from $S$. aureus ATCC 13565 cells. Image was obtained using the same exposure time as a. c Superposition

fluorescence intensity of hybridized versus nonhybridized samples was 5 to 20 -fold (mean increase of $11.18 \pm 6.40$ ), depending on the tested strain (Fig. 2a), allowing an unequivocal discrimination of both cellular subpopulations by observation of the superimposed histograms (Fig. 2b). On the other hand, no increase in fluorescence was generally observed for the closely-related $S$. aureus strain (Fig. 2a).

\section{Detection of $S$. epidermidis in blood samples by PNA FISH}

After FISH procedure optimization, the method was adapted for $S$. epidermidis detection in artificially seeded blood. For this, $10 \mathrm{~mL}$ of horse blood (ProBiológica, Portugal) were mixed with $90 \mathrm{~mL}$ of Tryptic Soy Broth (TSB) (VWR, Portugal) culture medium. The blood culture was then inoculated with a concentration of approx. $5 \mathrm{CFU} / \mathrm{ml}$, corresponding to $50 \mathrm{CFU}$ per $\mathrm{ml}$ of blood, a value generally considered indicative of infection (Haimi-Cohen et al. 2002), and incubated overnight at $37^{\circ} \mathrm{C}$, with agitation at $120 \mathrm{rpm}$. A non-inoculated culture was prepared in parallel and exposed to the same conditions as a control. One milliliter samples were recovered from each culture, diluted $1-10$ in sterile

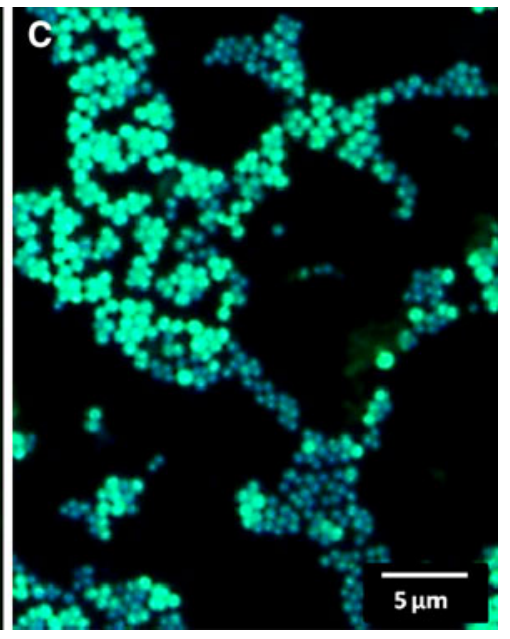

of the blue and green channel of the EF microscope showing S. aureus cells staining blue due to DAPI, and S. epidermidis with a bluish green color due to hybridization with the probe and staining with DAPI

water to promote the lysis of erythrocytes by osmotic stress, and then hybridized in suspension, as described above. Erythrocytes can have autofluorescence and the lysis of their cells simplifies the signal detection of the PNA probe. Triplicate samples were also analyzed by flow cytometry as described above.

As expected from the results obtained in pure culture, all $S$. epidermidis strains in blood culture were correctly identified using PNA FISH and flow cytometry (Fig. 2b, c). Once again, the Sep148 probe did not hybridize to the $S$. aureus reference strain, indicated by the unaltered fluorescence signal. Mean fluorescence intensities of labeled $S$. epidermidis strains were 8 to 12 -fold higher (mean increase of $10.30 \pm 1.62$ ) than the value obtained from nonhybridized $S$. epidermidis controls. Hybridized $S$. epidermidis and $S$. aureus cells from blood cultures were also easily discriminated by flow cytometric analysis (Fig. 2d), implying that the autofluorescence from $S$. aureus does not interfere with the correct detection of $S$. epidermidis-labeled cells.

\section{Conclusions}

The advantages of PNA over DNA probes have already been extensively covered in the literature. In 


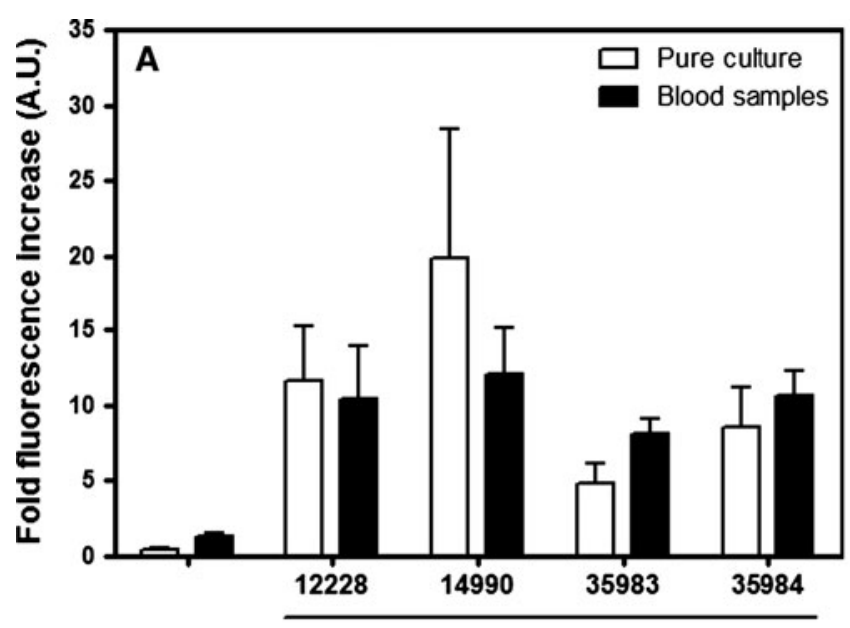

s. aureus

\section{S. epidermis}
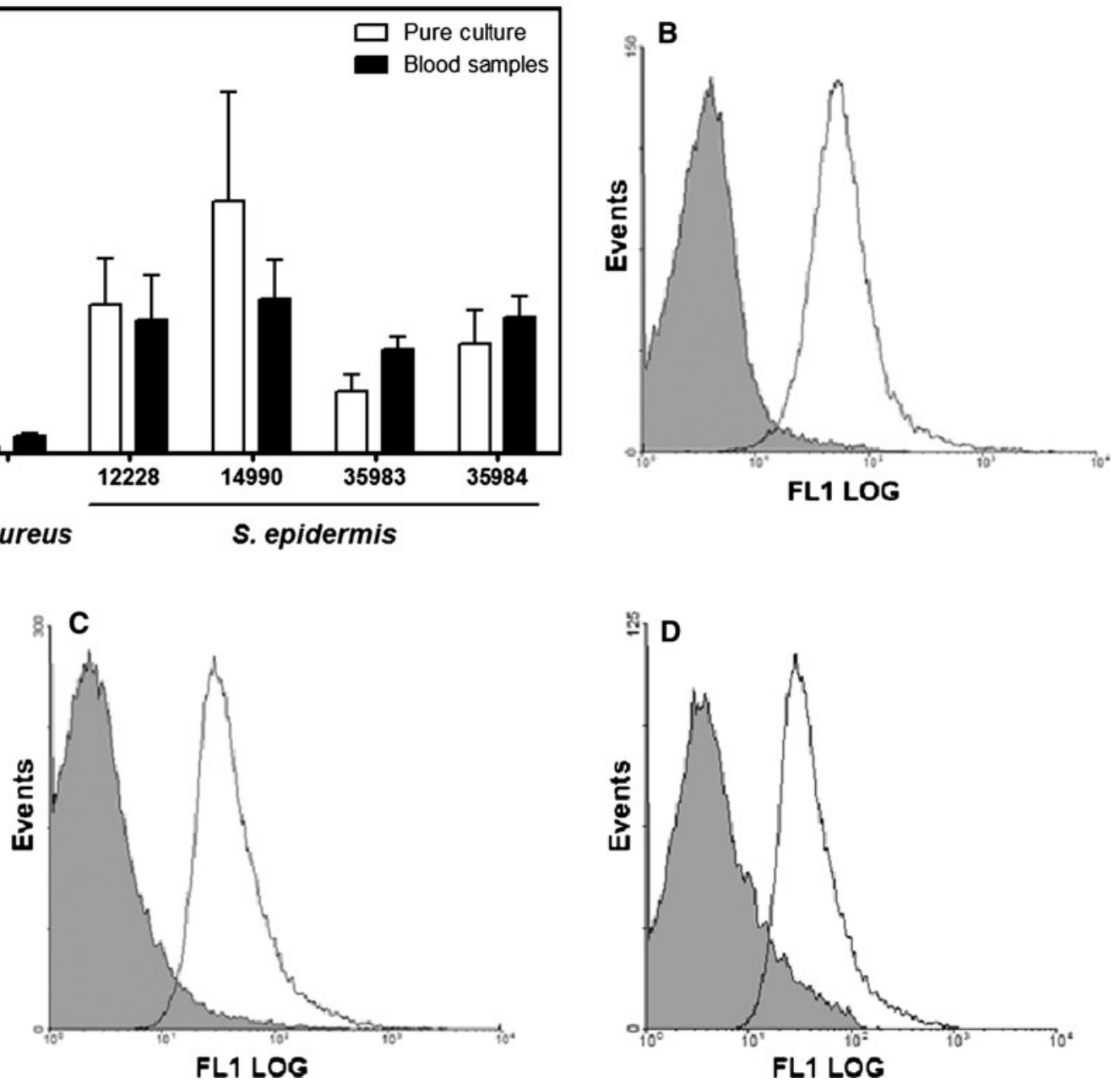

Fig. 2 Identification of $S$. epidermidis cells labeled with Sep148 by flow cytometry. a Increase in fluorescence intensity of four ATCC S. epidermidis-labeled strains in pure cultures and blood samples by flow cytometry. S. aureus was selected as a negative control for probe specific hybridization; b representative flow cytometric histograms of: non-hybridized

our case, it enabled us to perform the hybridization without the need for fastidious permeabilization steps involving enzymes and in a very short period of time $(<3 \mathrm{~h})$. In fact, the only other existing DNA FISH protocols involved either a permeabilization step where an enzyme mix was used (Krimmer et al. 1999), or took longer for the hybridization to occur (Zakrzewskaczerwinska et al. 1992). This was an expected result as the current state-of-the-art in DNA FISH methods for the closely-related $S$. aureus usually involves enzymes for permeabilization (e.g. Tavares et al. 2008), whereas PNA FISH methods (grey) and hybridized cells (white) of the S. epidermidis ATCC 35983 strain in pure culture, c representative flow cytometric histograms of: non-hybridized ( rey) and hybridized cells (white) of the S. epidermidis ATCC 35983 strain in blood samples and, d hybridized S. epidermidis ATCC 35983 cells (white) mixed with $S$. aureus (grey) in a blood sample

only require the application of ethanol (Hartmann et al. 2005).

The PNA FISH procedure described here has been shown to be a sensitive and specific method for the detection of $S$. epidermidis in blood samples. The versatility of the method implies that the detection of the bacterium can be performed either by flow cytometry or epifluorescence microscopy. The fact that it takes less than $3 \mathrm{~h}$ to perform after a pre-enrichment step means that it can be used as a rapid diagnostic method.

During the development of this method, we have also attempted an adaptation of PNA FISH for direct 
application in catheters, where S. epidermidis has been shown to form biofilms and be able to cause widespread infections. Detection has nevertheless been hindered by the low radius (high curvature) of the device (data not shown). Intermediate steps, such as the detachment of the cells from the catheter followed by a pre-enrichment step might therefore be necessary for a successful identification of the infectious agent.

In the future, the combination of Sep148 with other available probes can lead to the development of multiplex experiments to detect $S$. epidermidis and S. aureus simultaneously. Nonetheless, the low GC content in Sep148 implies that the optimal hybridization temperature for this probe is $5^{\circ} \mathrm{C}$ lower than the one for S. aureus (Perry-O'Keefe et al. 2001), which may, however, be overcome by including one or two bases to either side of the Sep148 sequence reported here to harmonize the incubation temperature for both probes.

Acknowledgements This work was supported by the Portuguese Institute Fundação para a Ciência e Tecnologia (PhD Fellowship SFRH/BD/29297/2006 and Post-Doc Fellowship SFRH/BPD/42208/2007).

\section{References}

Almeida C, Azevedo NF, Iversen C, Fanning S, Keevil CW, Vieira MJ (2009) Development and application of a novel peptide nucleic acid probe for the specific detection of Cronobacter (Enterobacter sakazakii) in powdered infant formula. Appl Environ Microbiol 75(9):2925-2930

Almeida C, Azevedo NF, Santos S, Keevil CW, Vieira MJ (2011) Discriminating multi-species populations in biofilms with peptide nucleic acid fluorescence in situ hybridization (PNA FISH). PLoS One 6(3):e14786

Ashelford KE, Weightman AJ, Fry JC (2002) PRIMROSE: a computer program for generating and estimating the phylogenetic range of $16 \mathrm{~S}$ rRNA oligonucleotide probes and primers in conjunction with the RDP-II database. Nucleic Acids Res 30:3481-3489

Barken KB, Haagensen JA, Tolker-Nielsen T (2007) Advances in nucleic acid-based diagnostics of bacterial infections. Clin Chim Acta 384:1-11

Cerqueira L, Azevedo NF, Almeida C, Jardim T, Keevil CW, Vieira MJ (2008) DNA mimics for the rapid identification of microorganisms by fluorescence in situ hybridization (FISH). Int J Mol Sci 9:1944-1960

Cole JR, Chai B, Farris RJ, Wang Q, Kulam SA, McGarrell DM, Garrity GM, Tiedje JM (2005) The ribosomal database project (RDP-II): sequences and tools for highthroughput rRNA analysis. Nucleic Acids Res 33:D294D296
Guimaraes N, Azevedo NF, Figueiredo C, Keevil CW, Vieira MJ (2007) Development and application of a novel peptide nucleic acid probe for the specific detection of Helicobacter pylori in gastric biopsy specimens. J Clin Microbiol 45:3089-3094

Haimi-Cohen Y, Vellozzi EM, Rubin LG (2002) Initial concentration of Staphylococcus epidermidis in simulated pediatric blood cultures correlates with time to positive results with the automated, continuously monitored BACTEC blood culture system. J Clin Microbiol 40:898-901

Hartmann H, Stender H, Schafer A, Autenrieth IB, Kempf VAJ (2005) Rapid identification of Staphylococcus aureus in blood cultures by a combination of fluorescence in situ hybridization using peptide nucleic acid probes and flow cytometry. J Clin Microbiol 43:4855-4857

Jukes L, Mikhail J, Bome-Mannathoko N, Hadfield SJ, Harris LG, El-Bouri K, Davies AP, Mack D (2010) Rapid differentiation of Staphylococcus aureus, Staphylococcus epidermidis and other coagulase-negative staphylococci and methicillin susceptibility testing directly from growth-positive blood cultures by multiplex real-time PCR. J Med Microbiol 59:1456-1461

Krimmer V, Merkert H, von Eiff C, Frosch M, Eulert J, Lohr JF, Hacker J, Ziebuhr W (1999) Detection of Staphylococcus aureus and Staphylococcus epidermidis in clinical samples by $16 \mathrm{~S}$ rRNA-directed in situ hybridization. J Clin Microbiol 37:2667-2673

Larsen MK, Thomsen TR, Moser C, Hoiby N, Nielsen PH (2008) Use of cultivation-dependent and -independent techniques to assess contamination of central venous catheters: a pilot study. BMC Clin Pathol 8:10

Markham NR, Zuker M (2005) DINAMelt web server for nucleic acid melting prediction. Nucleic Acids Res 33:W577-W581

McGinnis S, Madden TL (2004) BLAST: at the core of a powerful and diverse set of sequence analysis tools. Nucleic Acids Res 32:W20-W25

Nielsen PE, Egholm M, Berg RH, Buchardt O (1991) Sequence-selective recognition of DNA by strand displacement with a thymine-substituted polyamide. Science 254:1497-1500

Oliveira K, Haase G, Kurtzman C, Hyldig-Nielsen JJ, Stender H (2001) Differentiation of Candida albicans and Candida dubliniensis by fluorescent in situ hybridization with peptide nucleic acid probes. J Clin Microbiol 39:4138-4141

Perry-O'Keefe H, Rigby S, Oliveira K, Sorensen D, Stender H, Coull J, Hyldig-Nielsen JJ (2001) Identification of indicator microorganisms using a standardized PNA FISH method. J Microbiol Meth 47:281-292

Stender H, Lund K, Petersen KH, Rasmussen OF, Hongmanee P, Miorner H, Godtfredsen SE (1999) Fluorescence in situ hybridization assay using peptide nucleic acid probes for differentiation between tuberculous and nontuberculous mycobacterium species in smears of Mycobacterium cultures. J Clin Microbiol 37:2760-2765

Stender H, Fiandaca M, Hyldig-Nielsen JJ, Coull J (2002) PNA for rapid microbiology. J Microbiol Meth 48:1-17

Tavares A, Inacio J, Melo-Cristino J, Couto I (2008) Use of fluorescence in situ hybridization for rapid identification 
of staphylococci in blood culture samples collected in a portuguese hospital. J Clin Microbiol 46:3097-3100

Trebesius K, Panthel K, Strobel S, Vogt K, Faller G, Kirchner T, Kist M, Heesemann J, Haas R (2000) Rapid and specific detection of Helicobacter pylori macrolide resistance in gastric tissue by fluorescent in situ hybridisation. Gut 46:608-614
Vuong C, Otto M (2002) Staphylococcus epidermidis infections. Microbes Infect 4:481-489

Zakrzewskaczerwinska J, Gaszewskamastalarz A, Pulverer G, Mordarski M (1992) Identification of Staphylococcus epidermidis using a $16 \mathrm{~s}$ ribosomal-Rna-directed oligonucleotide probe. FEMS Microbiol Lett 100:51-58 